Anuario de

Derechos Humanos 2005 


\section{Las Convenciones de las Naciones Unidas y de la Organización de Estados Americanos contra la Corrupción}

José Zalaquett D.*

\begin{abstract}
I. Introducción
E ntre los días 3 y 5 de diciembre de 2004 se celebró en Santiago de Chile una Reunión Regional sobre Transparencia, Rendición de Cuentas y Lucha Contra la Corrupción en América, organizada por el Centro de Derechos Humanos de la Universidad de Chile y copatrocinada por Chile Transparente y por el Open Society Institute, institución esta última que financió la conferencia. El Documento de Referencia que se utilizó en la reunión se publica en la presente sección de este Anuario.
\end{abstract}

En dicho documento se da cuenta del surgimiento, en el plano internacional, del campo "transparencia, rendición de cuentas y lucha contra la corrupción", como el más reciente de los temas de ética política que han logrado concitar la atención de la opinión pública internacional y movilizar a sectores de la sociedad civil en diversos países, así como situarse en la agenda de organizaciones interestatales y en el temario de políticas públicas de distintos gobiernos.

En el plano de la ética política internacional a que nos referimos, la emergencia de este nuevo campo ha sido precedida, en las últimas décadas, por el desarrollo de otros, tales como los derechos humanos, incluyendo los derechos específicos de determinadas categorías o colectivos de personas, la protección del medio ambiente y movimientos en pro de la paz, de resolución de conflictos y de asistencia humanitaria.

El tema de la probidad pública tiene muchos puntos de contacto con el de los derechos humanos, además del hecho de que ambos pueden ser considerados como pertenecientes al ámbito cada vez creciente de cuestiones de ética política y acción ciudadana. En este sentido, cabe destacar que el desarrollo del concepto de democracia que ha tenido lugar, intensamente, desde el proceso internacional de democratización que comenzó en los años ochenta, incluye, centralmente, tanto el respeto y garantía a los derechos humanos como la probidad pública, transparencia y rendición de cuentas (accountability), entre otros elementos esenciales para la construcción de democracias cabales y para su fortalecimiento y sostenibilidad. Además, existen distintos puntos específicos del temario de probidad pública, como el derecho de acceso a información pública o el establecimiento de sistemas y reglas de sufragio que garanticen
* Co-Director del Centro de Derechos Humanos, Facultad de Derecho, Universidad de Chile. Miembro de la Comisión Interamericana de Derechos Humanos.
Este comentario está disponible en formato digital en www.anuariocdh.uchile.cl 
1 Si bien, en rigor, la Convención de las Naciones Unidas fue suscrita en el mes de diciembre de 2003 y este Anuario da cuenta de desarrollos relevantes ocurridos durante 2004, el proceso de ratificaciones ha continuado a lo largo de este último año y, en todo caso, es conveniente dar cuenta sucinta de estas convenciones, en perspectiva comparada, en esta sección sobre temas emergentes.

2 Información contenida en http://www.oas.org/ juridico/spanish/firmas/ b-58.html, consultado el 4 de mayo de 2005.

3 Información contenida en http://www.undoc.org/ crime_signatures corruption.html, consultado el 2 de mayo de 2005

4 La Convención de las Naciones Unidas Contra la Corrupción estuvo abierta a la firma de todos los Estados del 9 al 11 de diciembre de 2003 en Mérida, México, y después de esa fecha permanece abierta a la firma en la Sede de las Naciones Unidas en Nueva York, hasta el 9 de diciembre de 2005. Su artículo 67.2 abre también la Convención a la firma de las organizaciones regionales de integración económica, pero para los efectos de su entrada en vigor se consideran solamente las ratificaciones por parte de los Estados. procesos de elección popular justos, universales y transparentes, los cuales se pueden abordar, asimismo, desde la perspectiva de la libertad de expresión (en su faceta de buscar y recibir información) y de los derechos políticos, respectivamente. También se da una vinculación entre ambos campos en lo que toca a derechos económicos, sociales y culturales, en la medida en que la transparencia y la rendición de cuentas son instrumentos que permiten o facilitan la fiscalización por parte de la sociedad civil de las políticas públicas y de la elaboración y ejecución de presupuestos públicos, nacionales o locales.

No obstante estos puntos de contacto, es preciso reconocer que el campo emergente de probidad pública y lucha contra la corrupción tiene su identidad y características propias, tanto en el plano normativo y organizacional, como en lo que se refiere a políticas públicas y medidas específicas para lograr los objetivos que se persiguen; por ello, no puede ser entendido como una simple extensión de la temática de los derechos humanos.

En el ya mencionado Documento de Referencia se reseña la evolución del campo de transparencia, rendición de cuentas y lucha contra la corrupción y se señalan someramente sus principales componentes normativos e institucionales. En esta nota se complementa dicha información mediante un resumen y comparación de los principales componentes normativos internacionales, esto es, la Convención Interamericana Contra la Corrupción (en adelante, "la Convención Interamericana") y la Convención de las Naciones Unidas Contra la Corrupción (en adelante, "la Convención de las Naciones Unidas"), los dos principales instrumentos sobre esta materia de los que son parte o signatarios los países latinoamericanos, incluido Chile ${ }^{1}$.

\section{Las Convenciones de la OEA y de las Naciones Unidas: Aspectos comunes}

La Convención Interamericana fue adoptada en Caracas el 29 de marzo de 1996. Todos los países americanos que tienen representación en la OEA (esto es, todos excepto Cuba) la han suscrito y, salvo Barbados, todos los Estados signatarios han depositado instrumentos de ratificación o adhesión ${ }^{2}$. La Convención entró en vigor el 6 de marzo de 1997.

La Convención de las Naciones Unidas Contra la Corrupción ha sido suscrita por 115 países, incluidos todos los iberoamericanos, y ratificada por 18 países, entre ellos tres países iberoamericanos: El Salvador, México y Perú ${ }^{3}$. Conforme a lo dispuesto en su artículo 68, esta Convención entrará en vigor el nonagésimo día después de la fecha en que se haya depositado el trigésimo instrumento de ratificación, aceptación, aprobación o adhesión por parte de Estados signatarios ${ }^{4}$.

Pese a que ambas Convenciones son diferentes en cuanto a su ámbito territorial de aplicación, al número y detalle de sus disposiciones y a importantes elementos de contenido (que se señalan más adelante), 
presentan muchas características comunes. Entre ellas, las principales son las siguientes:

a) Los intereses y valores explícitos que dan pie a las normas respectivas. En la mayor parte de las convenciones multilaterales, los intereses y valores -o, si se quiere, los bienes jurídicos- que se busca proteger, se encuentran expresados en el preámbulo. Si bien esa sección inicial de la Convención de las Naciones Unidas es más detallada que la de la Convención Interamericana, el contenido es muy semejante en ambos preámbulos. Los valores o bienes jurídicos generales que se busca resguardar frente a los problemas y amenazas que plantea la corrupción son: (i) la estabilidad política y seguridad de las sociedades; (ii) la integridad y legitimidad de las instituciones democráticas; (iii) la ética (o la moral social), la justicia y el imperio de la ley; (iv) el desarrollo integral y sostenible de los Estados y los pueblos; $(v)$ el orden público económico, que puede verse amenazado por las distorsiones que la corrupción introduce en la economía; (vi) la integridad y calidad de la gestión pública y la defensa del patrimonio público.

b) El propósito o finalidad. Ambas convenciones explícitamente señalan como propósito o finalidad promover y fortalecer medidas de prevención y combate contra la corrupción y promover la cooperación internacional para este objetivo ${ }^{5}$.

c) Medidas específicas de carácter preventivo y de penalización. En consonancia con los propósitos o finalidades que expresan, ambas convenciones detallan medidas preventivas y de penalización, siendo las normas respectivas de la Convención de las Naciones Unidas mucho más numerosas y detalladas. Las medidas preventivas consisten principalmente en: (i) sistemas y normas sobre contratación de funcionarios públicos, remuneraciones, códigos de conducta y capacitación; (ii) mecanismos de transparencia respecto de los haberes e intereses de funcionarios públicos; (iii) sistemas que aseguren equidad y transparencia en las adquisiciones públicas; (iv) diversos mecanismos y formas de control ex ante o ex post; ( $v$ ) la protección de denunciantes. Entre las disposiciones sobre penalización, ambas convenciones coinciden en cuanto a la técnica legislativa de describir determinadas conductas delictivas y establecer la obligación de los Estados de tipificar tales conductas en su ordenamiento jurídico interno, si aún no lo han hecho.

\section{Las Convenciones de la OEA y de las Naciones Unidas: Principales diferencias}

En un análisis comparado de ambas convenciones se hace evidente el peso que han tenido los sucesos relevantes ocurridos en el término de más de siete años que media entre la suscripción de ellas. Por una parte, el campo de la lucha contra la corrupción experimentó un significativo desarrollo en ese período. Por otra, los ataques terroristas del 11 de septiembre de 2001 contra Nueva York y Washington D.C., contribuyeron a poner aún más de relieve las preocupaciones
5 Artículo I de la Convención de las Naciones Unidas y Artículo II de la Convención Interamericana. El primero de ellos añade en su letra c), la finalidad positiva de "promover la integridad, la obligación de rendir cuentas y la debida gestión de los asuntos y los bienes públicos". 
6 Estas citas están tomadas del Preámbulo de las respectivas convenciones.

7 Capítulo III de esta Convención.

8 El Artículo IX, inciso primero, de la Convención Interamericana establece lo siguiente: "Con sujeción a su Constitución y a los principios fundamentales de su ordenamiento jurídico, los Estados Partes que aún no lo hayan hecho, adoptarán las medidas necesarias para tipificar en su legislación como delito, el incremento del patrimonio de un funcionario público con significativo exceso respecto de sus ingresos legítimos durante el ejercicio de sus funciones y que no pueda ser razonablemente justificado por él".

9 Artículos 21, 22, 23 y 25 de la Convención de las Naciones Unidas.

${ }^{10}$ Artículo 26.

11 Artículos 24 y 27.

12 Artículo 29. internacionales por la seguridad y estabilidad de las democracias frente a la delincuencia organizada y a la delincuencia económica, incluido el blanqueo de dinero.

En razón de lo anterior, si bien la estructura general de ambos instrumentos no es significativamente diferente, la Convención Interamericana comprende 28 artículos, en tanto que la de las Naciones Unidas tiene 71, los cuales son, además, y por lo general, mucho más extensos.

Amén del hecho de que las normas de la Convención de las Naciones Unidas son más numerosas y detalladas que las de la Convención Interamericana, los siguientes aspectos específicos reflejan, decidoramente, el avance de la conciencia internacional sobre estos temas en el período que media entre la firma de ambos instrumentos:

a) En tanto que la Convención Interamericana "(reconoce que) la corrupción tiene, en algunos casos, trascendencia internacional", la Convención de las Naciones Unidas expresa, de modo más categórico, "(la convicción de que) la corrupción ha dejado de ser un problema local para convertirse en un fenómeno transnacional que afecta a todas las sociedades y economías..." ${ }^{6}$.

b) El catálogo de conductas delictivas que los Estados Parte se obligan a tipificar, si no lo han hecho ya, que contiene la Convención de las Naciones Unidas, es más completo y preciso ${ }^{7}$. En particular esta convención se ha cuidado de: (i) incorporar en sus descripciones referencias explícitas a elementos subjetivos del delito ("cuando se cometa intencionalmente" o "a sabiendas"); esto se explica en buena medida por los reparos y críticas que, desde el punto de vista de la teoría penal, había recibido la descripción del enriquecimiento ilícito incluida en la Convención Interamericana ${ }^{8}$, que podía ser considerada como estableciendo una forma de responsabilidad penal objetiva o la inversión del peso de la prueba; (ii) incluir descripciones de las conductas delictivas de soborno y de malversación o peculado de bienes en el sector privado, así como la figura de blanqueo del producto del delito y la obstrucción a la justicia ${ }^{9}$; (iii) contemplar expresamente la responsabilidad de las personas jurídicas ${ }^{10}$; (iv) establecer normas más precisas sobre distintas formas de participación en la comisión del delito ${ }^{11}$; (v) disponer la obligación de los Estados de establecer un plazo de prescripción amplio para iniciar procesos por los delitos que describe, y un plazo mayor, o bien la interrupción de la prescripción, cuando el presunto delincuente haya eludido la administración de justicia ${ }^{12}$.

c) La cláusula de jurisdicción de la Convención de Naciones Unidas es más amplia que la cláusula respectiva de la Convención Interamericana. Ambas incluyen los principios de territorialidad, de personalidad activa y de "extraditar o juzgar" (aut dedere, aut judicare), pero la primera de ellas agrega el principio de personalidad pasiva, el cual no está contemplado en la segunda. 
d) La Convención de las Naciones Unidas es incomparablemente más completa y detallada en lo que toca a las medidas de cooperación internacional sobre: (i) extradición, traslado de personas condenadas a cumplir una pena, asistencia judicial recíproca, remisión de actuaciones penales, intercambio de informaciones e investigaciones conjuntas para hacer cumplir la ley y técnicas especiales de investigación; (ii) recuperación de activos y decomiso, así como mecanismos internacionales de inteligencia financiera; (iii) capacitación de personal encargado de combatir la corrupción, asistencia técnica e intercambio de información ${ }^{13}$.

e) En su Capítulo VII, la Convención de las Naciones Unidas establece como mecanismo de aplicación una Conferencia de los Estados Parte. Entre otras facultades, este cuerpo facilitará las actividades de cooperación, examinará periódicamente la aplicación de las normas de la Convención por sus Estados Parte y formulará recomendaciones para mejorar la Convención y su aplicación. El Secretario General de las Naciones Unidas dispondrá los servicios de Secretaría para la Conferencia de los Estados Parte. La Convención Interamericana no explicita mecanismos de aplicación. Sin embargo, los Estados Parte, aprobaron el Acta de Buenos Aires ${ }^{14}$, que establece un Mecanismo de Seguimiento de la Implementación de la Convención Interamericana Contra la Corrupción (MESICIC), consistente en una Conferencia de Estados Parte y un Comité de Expertos. Este último cuerpo se ha reunido varias veces para examinar los informes de avances en la implementación de la Convención Interamericana que le hacen Ilegar los Estados Parte. El Comité estimula la participación de la sociedad civil de los respectivos países en este proceso, recibiendo y tomando en cuenta informes y comentarios que organizaciones y grupos no gubernamentales le hagan llegar sobre la materia ${ }^{15}$. En la presente sección de este Anuario se consignan las recomendaciones del Comité de Expertos del MESICIC sobre el cumplimiento de la Convención Interamericana por parte de la República de Chile ${ }^{16}$.
${ }^{13}$ Capítulos IV, V y VI de la Convención de las Naciones Unidas.

${ }^{14}$ El Acta de Buenos Aires fue consensuada en una reunión de los Estados Parte de la Convención Americana que tuvo lugar en dicha ciudad entre el 2 y 4 de mayo de 2001. Por Resolución AG/ RES.1784(XXXI-0/01), de 5 de junio de 2001, la Asamblea General de la OEA tomó conocimiento con beneplácito de dicho consenso y solicitó a la Secretaría General de la OEA que brinde servicios de Secretaría al MESISIC.

15 Este mecanismo de aplicación que consiste en solicitar y recibir informes de parte de los Estados y de otras fuentes, discutirlos y formular observaciones $y$ recomendaciones a los Estados, se aplica también en sistemas de protección de los derechos humanos. En el sistema de Naciones Unidas este método es utilizado por diversos organismos convencionales de aplicación y protección, comenzando por el primero de ellos, el Comité de Derechos Humanos, establecido por el Pacto Internacional de Derechos Civiles y Políticos. El Comité de Derechos Económicos, Sociales y Culturales, para cuyo trabajo esta metodología es fundamental, no fue establecido por el Pacto respectivo sino por Resolución 19856/17, adoptada el 28 de mayo de 1985 por el Consejo Económico y Social de las Naciones Unidas.

16 Informe aprobado en la Quinta Reunión del Comité de expertos del MESISIC celebrada entre el 2 y 6 de febrero de 2004 . Documento de la OEA SG/ MESISIC/doc. 89/rev. 4. 